\title{
A Decision Support Tool for Cost Mastering in Urban Self-Construction: The Case of Cameroon
}

\author{
Marcelline Blanche Manjia*, ${ }^{1}$, V. Foka Kedang ${ }^{1}$, P. Louzolo-Kimbembe ${ }^{2}$ and C. Pettang ${ }^{1}$ \\ ${ }^{1}$ Laboratory Civil Engineering and Conception Science, Department of Civil Engineering, National Advanced School of \\ Engineering ,University of Yaounde I; P.O. Box. 8390, Yaoundé, Cameroon; ${ }^{2}$ Department of the Exact Sciences, Higher \\ Teacher Training School, P.O. Box. 237 Brazzaville, Congo
}

\begin{abstract}
The critical housing shortage in cities of the developing countries like Cameroon generates an ever-growing desire to increase housing supply. The main group of actors in this domain are by and large the formal sector, while the informal sector is still inactive. Because of the legalities and costs associated with the formalities surrounding the provision of formal housing, the majority of urban residents are bypassed by the formal housing policies. The only alternative for them is thus self-construction. This mode of housing provision, although difficult, has become a dominant mode of providing housing within the construction sector of the developing countries. Consequently, this mode of housing provision now features in mainstream specialised literature, with an aim to promote the sector. Furthermore, several techniques of mastering self construction costs have been elaborated. However, given the complexity of abundant (albeit unqualified) labour, there is still a case for further research in the self-construction forms of housing, especially in terms of their adaptability. The sector is criticised for being characterised by unclear cost accounting methods, as well as the ubiquitous below-par management techniques which themselves lead to delays in the completion of such housing projects. In light of the foregoing exposition, the article presents a method of estimating labour costs based on a developed matrix model. Through the introduction of the finite dimensional vector space made up of the standard tasks, the model draws up a direct relationship between the quantity of work and the labour cost. The illustration of this new approach, through a case study shows that it is possible to reduce the labour cost of up to $37 \%$, compared to the simple matrix method as examined by other researchers. The Developed Matrix Approach (MASTA) based on standard tasks thus constitute a decision-making tool that is not only for optimisation of productivity but also a symbol of good management
\end{abstract}

Key Words: Self-help housing, labour, costs, management, matrix, decision-making tool.

\section{INTRODUCTION}

The objectives of a construction project can be summarized in three categories: technical performances, adherence to prescribed duration of the project, and not exceeding budget or costs. In the developing countries (D.C) in general, the construction sector has a cocktail of problems which compromise attainment of the above three objectives. In $\mathrm{Ni}$ geria, for example, $70 \%$ of the projects are completed well beyond their prescribed duration [1]. In addition, the problems encountered in this sector are those to do with the determination of the causes of costs overruns and datelines, which can sometimes be attributed to bad weather, strikes, financial difficulties [2], materials mismanagement, slow decision-making, and irregularities in the design, planning and execution of the projects [3], deficiencies in management of the contract or the on-the-site modifications of the project [4]. According to other researchers, it is primarily due to the inappropriate techniques of costs estimation and the bad practices of project management [5].

In Cameroon, the construction domain is dominated by the informal sector. The informal sector of the housing

*Address correspondence to this author at the Laboratory Civil Engineering and Conception Science, Department of Civil Engineering, National Advanced School of Engineering ,University of Yaounde I; P.O. Box. 8390, Yaoundé, Cameroon; Tel: (237)99863707; E-mail: mbmanza@yahoo.fr industry could be defined as the whole range of the unlawful mechanisms which are used in undertaking housing construction surveys, the supply chain management, the employment and the remuneration of the labour, and financing, which are primarily based on personal saving, the Rotating Savings and Credit Associations (ROSCA). ROSCA is a group of individuals who agree to meet for a defined period of time in order to save and borrow together. In general, ROSCA are the poor man's bank, where money is not idle for long but changes hands rapidly, satisfying both consumption and production needs) and above all, procurement processes [6]. In the self construction, some weaknesses are noted, in particular, the unstable financial standing, lack of monitoring and control of work, the poor qualification and instability of the labour/manpower, prevalence of odd jobs executed by jobber and the use of materials and equipment acquired dubiously.

In Yaoundé town, the second largest city in Cameroon (with 1, 600, 000 inhabitants), the demand for decent and affordable housing keeps on skyrocketing and is expected to remain like this for a long time. Besides, the demand is never met as it far outstrips supply. This is despite the government's policy to encourage national organizations to provide more formal housing. Consequently, "self construction"(housing construction executed by individuals without any formal legal procedure hence may not be in conformity with any planning regulations) which tries to make up the 
housing deficit has become a common practice. The labour used in this sector is very varied and is divided into two groups: assistance, made up of the family and relatives; professionals gathering of jobbers, qualified technicians and workmen trained on the job.

Previous studies [7] have proved that the promotion of the sector of the self construction could be done by the optimization of labour, building materials and the planning of the tasks, probably supported by credit facilities.

\section{Aims and Scope of the Research}

The search for a direct aid to the self constructors has been a growing quest among many researchers, with several tools proposing: the facilitation of the process of obtaining the licence to build [8], the methods of saving by protective sackings [9], and the control of scientific and technical parameters (costs, times, quality) of the self project construction [10].

With regards to this last aspect, especially the cost mastering the essential parameters of a construction project cost which are materials, labour and overheads (equation 1), accurate estimation methods and good management practises are must very important.

$C_{T}=C_{M a}+C_{M O}+C_{M G}$

Where, $\mathrm{C}_{\mathrm{T}}=$ Total construction cost;

$\mathrm{C}_{\mathrm{Ma}}=$ materials cost $; \mathrm{C}_{\mathrm{MO}}=$ labour cost;

$\mathrm{C}_{\mathrm{MG}}=$ cost of management or overheads (insurances, rents, guarding, vehicles, drivers...)

The importance of the construction cost mastering; especially the labour cost in the production of housing in self construction has led many researchers to reflect on a suitable tool able to help the self constructor to reduce delays and cost overruns of construction projects.

\section{Preceding Studies}

Many techniques for cost mastering in construction were developed by previous researchers. We can classify them into three groups: There are fast methods (unit method, covered area method...), there are detailed methods such as analytical methods [11], the simple matrix approaches [12, 13], and finally there are automatical methods such as UNIFORMAT II [14].

Fast methods are based on summary information on the project such as the theoretical useful surface area, theoretical volume that one multiple by current unit prices and who are sometimes not very precise. In equation (1), the proportion of $65 \%$ is often considered at the cost of materials, $20 \%$ at the cost of the labour and $15 \%$ for the means of management

The cost estimated using these methods does not make it possible to the self builder with low income to plan (according to his incomes) the execution of different sub structures of the project, which can cover several years. These methods are thus reserved to the specialists in construction and are often used for the invitations to tender

Detailed methods are practical for cost estimation and control, because numerous parameters of the cost are integrated:
In the simple matrix approach [13] based on the product of tables, the impact of the materials cost (CMa) was highlighted for the most current construction types, namely: masonry brick, stabilized ground blocks, wood and mud mortar gathering. The expression of $\mathrm{C}_{\mathrm{Ma}}$ is written as follow:

$\mathrm{C}_{\mathrm{Ma}}=\sum_{z=1}^{\mathrm{p}} \mathrm{Q}_{z} \mathrm{P}_{z}$

Where $\mathrm{p}=$ the number of materials types;

$\mathrm{Q}_{\mathrm{Z}}=$ the necessary quantity of material index $z$;

$\mathrm{P}_{\mathrm{z}}=$ the unit price of material index $j$

The same approach was extended to the evaluation of the labour cost [15] by using, as variables, the manpower by trade, the daily income of a workman, the duration of the realization per sub-structure. Thus, the labour cost, in the equation (1), is given by the following expression:

$C_{M O}=(N \times R) \times D$

Where $\mathrm{N}$ is a spreadsheet relating to the number of workers per trade, $\mathrm{R}$ a spreadsheet relating to the worker's daily income, and $\mathrm{D}$ a spreadsheet relating to realization duration.

From equation 3, they can write: $C_{M O}=\left(L_{i j}\right)=\left(n_{i j} R_{i j} d_{i j}\right)$ $\mathrm{n}_{\mathrm{ij}}$ : the number of workers for the task $\mathrm{j}$ and in the sub structure SOi;

Rij: daily income of one worker for the task $\mathrm{j}$ realization;

$\mathrm{d}_{\mathrm{ij}}$ : duration of the realization of the substructure SOi for the task j.

if the realization of the substructure SOi doesn't include the task $\mathrm{j}$, then $\mathrm{n}_{\mathrm{ij}}=0$

The simple matrix approach is easy and practical for the costing of the materials (equation 2), but for the labour costing (equation 3), it does not seem to give a better precision for the evaluation of the productivity of a worker in the realization of a given task. For lack of external checking and supervision, the $\mathrm{R}_{\mathrm{ij}}$ number does not highlight the quantity of work really carried out during eight working hours daily. Indeed, because of the insufficiency of the means of control and monitoring in this sector, personal elements such as tiredness, the behaviour of the workman, the lack of motivation and the instability of the manpower of the labour (specially the jobbers), do not make it possible to appreciate exactly the value the productivity of a jobber compared to a precise task. Indeed, the value of a Dij element of the spreadsheet D (working hour) can increase very quickly while the quantity of work remains constant. Then for a given task, the simple matrix approach [13] does not establish a direct relation between the worker's daily income and the quantity of work effectively carried out.

From an analytical method [11], the term $\mathrm{C}_{\text {мо }}$ of the equation (3) is written as follow (equation 4):

$$
C_{M O}=\sum_{i=1}^{N T} T_{i} M_{i} S_{i}
$$


Where $N T=$ the number of different tasks;

$\mathrm{T}_{i}=$ workload necessary to carry out the standard task $i$

$M_{i}=$ the number of times that this task will have to be repeated; $\mathrm{S}_{i}=$ unit labour cost per hour for one worker carrying out the task $i$

The equation (4), rather accurately presents the labour component in the construction cost.

Nonetheless, at a given stage of the project, this formula does not sufficiently establish the economic weight of each element which constitutes it. Indeed, the difficulty related to this formula is relative to the inventory and the subdivision of the tasks. But, in self construction, the incidence of the jobbers makes little specifies the measurement of the unit labour cost value $S_{i}$ (equation 3 ). In the same way, the determination of $T_{i}$ value (workload necessary to carry out the standard task $i$ ) can depend on certain external factors difficult to control (small equipments, characteristic of the site, experiment, behaviour of the workman, etc).

The statistical-matrix approach [10] combines simple matrix approach and multiple linear regression "to explain" the total construction cost $\mathrm{K}$, according to $r$ independent variables, with the historical data from the observation of an $N$ - size statistical sample ( $\mathrm{N}$ lodgings).

Thus:

$$
K=A_{O}+\sum_{j=1}^{r} A_{j} c_{j}+\varepsilon
$$

$\mathrm{K}$ is the exogenous variable (to be explained); $\left(c_{\mathbf{j}}\right)_{\mathbf{1} \leq \mathbf{j} \leq \mathbf{r}}$,are endogenous variables

A0 represents the constant term; where $\left(A_{j}\right)_{1 \leq j \leq r}$ are regression coefficients (parameters); they express the total lodging cost $\mathrm{K}$ as follow:

for a given lodging $i$,

$\mathbf{1} \leq i \leq N: K_{i}=A_{0}+\sum_{j=1}^{p} A_{j} c_{i j}+\sum_{j=p+1}^{q} A_{j} c_{i j}+\sum_{j=q+1}^{r} A_{j} c_{i j}+\varepsilon_{i}(6)$

$\left(c_{j}\right)_{1 \leq j \leq p}$ relate to the cost of materials;

$\left(c_{j}\right)_{p+1 \leq j \leq q}$ relate to the cost of the labour;

$\left(c_{j}\right)_{q+1 \leq j \leq r}$ relate to the cost of the overheads;

$\varepsilon_{i}$ represents the random error (individual worker behaviour).

According to equations 5 and 6 , the quantity $c_{i j}$ is the value of the variable $\left(c_{j}\right)_{1 \leq j \leq r}$

The statistical-matrix approach [10] shows that the estimation of total construction cost $\mathrm{KT}_{\mathrm{T}}$ can be carried out using five parameters, one relating to labour cost and four relating to materials cost (roofing and sealing, masonry, carpentry and joinery, plumbing with a tolerance margin characterized by confidence intervals of the regression coefficients.

The final cost estimation is obtained by the following formula (equation 7) $K_{T}=A_{0}+A_{1} X_{1}+A_{2} X_{2}+A_{3} X_{3}+$ $A_{4} X_{4}+\ldots+A_{m} X_{m} \pm M(7)$

Where: $m<r$

$X 1, X 2, X 3, \ldots, X m$ : are exogenous variables to the total cost.

$A_{0}$ is constant. The values of regression coefficients $\left(A_{j}\right)_{1 \leq j \leq m}$ are respectively chosen in intervals $\left[A_{1, \text { inf }} ; A_{1, \text { sup }}\right] ;\left[A_{2, \text { inf }} ; A_{2, \text { sup }}\right] ; \ldots ;\left[A_{m, \text { inf }} ; A_{m, \text { sup }}\right]$ given by the statistical software.

If $K_{T_{\text {sup }}}$ and $K_{T_{\text {inf }}}$ represent the high estimation and the low estimation of construction cost, obtained respectively from the maximum and minimal values of $\left(A_{j}\right)_{1 \leq j \leq m}$,

Then: $M=\left(K_{T_{\text {sup }}}-K_{T_{\text {inf }}}\right) / 2$ represents the tolerance margin

The statistical matrix approach is a parametric estimation method which makes it possible to quickly obtain the project cost starting from a reduced number of variables. But, any estimate whatever its precision, cannot only guarantee the control of the cost of construction [5]; it constitutes only one of the aspects of the control of the project cost, the realisation stage being able to undergo various disturbances able to go beyond initial budget. Very often it was noted that even with financial resources available, the self constructor has many difficulties in carrying out his construction project. The nature of those difficulties could thus depend on the labour management. Indeed, the labour factor has an important significance in the costs estimating stage, even in the project execution stage. In addition, any inadequacy between a tasks and the workman qualification can have heavy penalty so as: work resumption; never-ending execution time; excessive costs of construction; low security and durability of the building.

Automatical methods such as UNIFORMAT II are more detailed than the methods above, but his utilisation need additional costs for training. The UNIFORMAT II approach is quite precise and makes it possible to directly calculate the construction total cost, including overheads. However, it cannot always adapted in self construction projects, for lack of effective means of self-checking.

The above estimation and mastering cost models have each advantage and disadvantage. The common factor of theses disadvantages is their adaptability to labour complexities in the informal sector, dominant in construction domain of must of Developing countries. This paper presents a cost estimation method based on the developed matrix algebra which could help the self constructor to predict and control 
construction cost, taking into consideration the labour specificities and complexities in informal sector.

\section{METHODOLOGY}

The method that we intend to use is deterministically and hypothetical deductive, based on developed matrix algebra. We suppose that the cost of the labour can be expressed in a vector space with finite dimension. Thus on the scale of sub structure, the labour cost would be a linear combination of vectors whose components depend at the same time on sub structure and the task to be carried out. For sub structure $\mathrm{SO}_{\mathrm{i}}$ (i fixed), the labour cost can be written as follows

$$
C_{M O i} \equiv \overrightarrow{M O_{i}}=\sum_{j=1}^{t} \mu_{i j} \overrightarrow{m_{j}} ; \forall 1 \leq i \leq s
$$

The first part of this approach aim to decompose the project into elementary tasks, then to choice a basis vector, and lastly to determine the main components project cost by matrix calculation. Fig. (1) presents the diagram of our method.

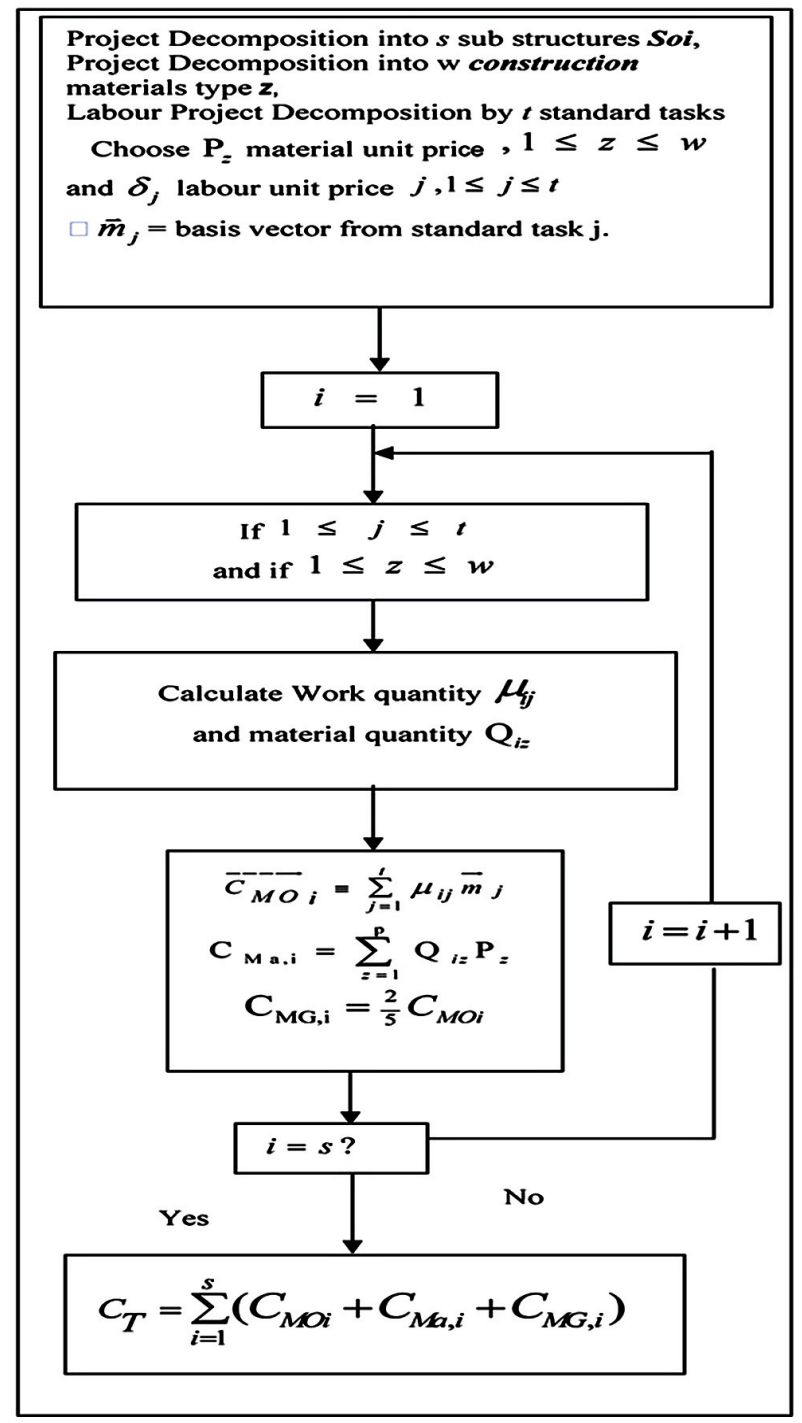

Fig. (1). Diagram of the method: Matrix Approach based on Standard Tasks (MASTA).
For a self construction given project, we give in the Table $\mathbf{1}$, the inventory of the standards tasks to execute. In the following part, $\xi$ indicates the set of all the expenditure relating to labour for a self construction project. The nonempty set $\xi$ will be provided with the usual laws as vector addition and scalar multiplication in the real numbers field $I R$. Then $(\xi$, $+, \bullet)$ is a finite - dimensional vector space over the field IR consisted by the basis $\left\{\vec{m}_{j}\right\}$.

For each standard task $j$, we make corresponding a finite family of $t$ vectors in the Following way:

$\left\{\begin{array}{l}\vec{m}_{1}=\left(\delta_{1}, 0,0, \ldots, 0,0\right) ; \vec{m}_{2}=\left(0, \delta_{2}, 0, \ldots, 0,0\right) ; \\ \ldots ; \\ \vec{m}_{j}=\left(0,0, \ldots, \delta_{j}, \ldots, 0,0\right) ; \ldots ; \vec{m}_{t}=\left(0,0, \ldots, 0, \delta_{t}\right)\end{array}\right.$

Where $\overrightarrow{m_{j}}$ is the vector of the basis related to the standard task $j ; t$ is the number of standard tasks.

For a given $j, 1 \leq j \leq t \vec{e}_{j}=\mathrm{j}$ th vector of the usual basis in $\left(I R^{t},+, \times\right)$, and $\vec{m}_{j}=\delta_{j} \vec{e}_{j}$

According to equation $8, \mu_{\mathrm{ij}}$ represents the corresponding scalar.

Then, we suppose that the correspondence $f$ below is injective (equation 10).

$$
\left\{\begin{array}{l}
\xi \stackrel{f}{\longrightarrow}\left(I R^{t},+, \times\right) \\
d \rightarrow\left(d_{1}, d_{2}, \ldots, d_{t}\right)=\left(\delta_{1} \sum_{i=1}^{s} \mu_{i 1}, \delta_{2} \sum_{i=1}^{s} \mu_{i 2}, \ldots, \delta_{t} \sum_{i=1}^{s} \mu_{i t}\right)
\end{array}\right.
$$

This leads us to the determination of the matrices relating to the various components of construction cost.

\section{Matrix Definition}

In the following part, $\left[M_{l, c}\right]=\left(\omega_{i j}\right)_{1 \leq i \leq l ; 1 \leq j \leq c}$ indicates an $l$ by $c$ matrix,

The diagonal matrix resulting from $\left[M_{l, c}\right]$ will be noted as $\left[M_{c, c}^{\prime}\right]$;

The transpose of a matrix $\left[M_{l, c}\right]$ will be noted $\operatorname{as}^{T}\left[M_{l, c}\right]$.

The product of two matrices $\left[M_{l, c}\right] \times\left[N_{c, k}\right]=\left[A_{l, k}\right]$ will be perfectly defined by that their units in the real numbers field $I R$.

$\left[I_{s, 1}\right]$ is a column vector whose the $s$ elements have the value 1 .

From the data relating to the given construction project, we define the following matrices $\left[\mu_{s, t}\right]$ and $\left[U_{3, t}\right]$ relating to 
Table 1. The Standard Tasks

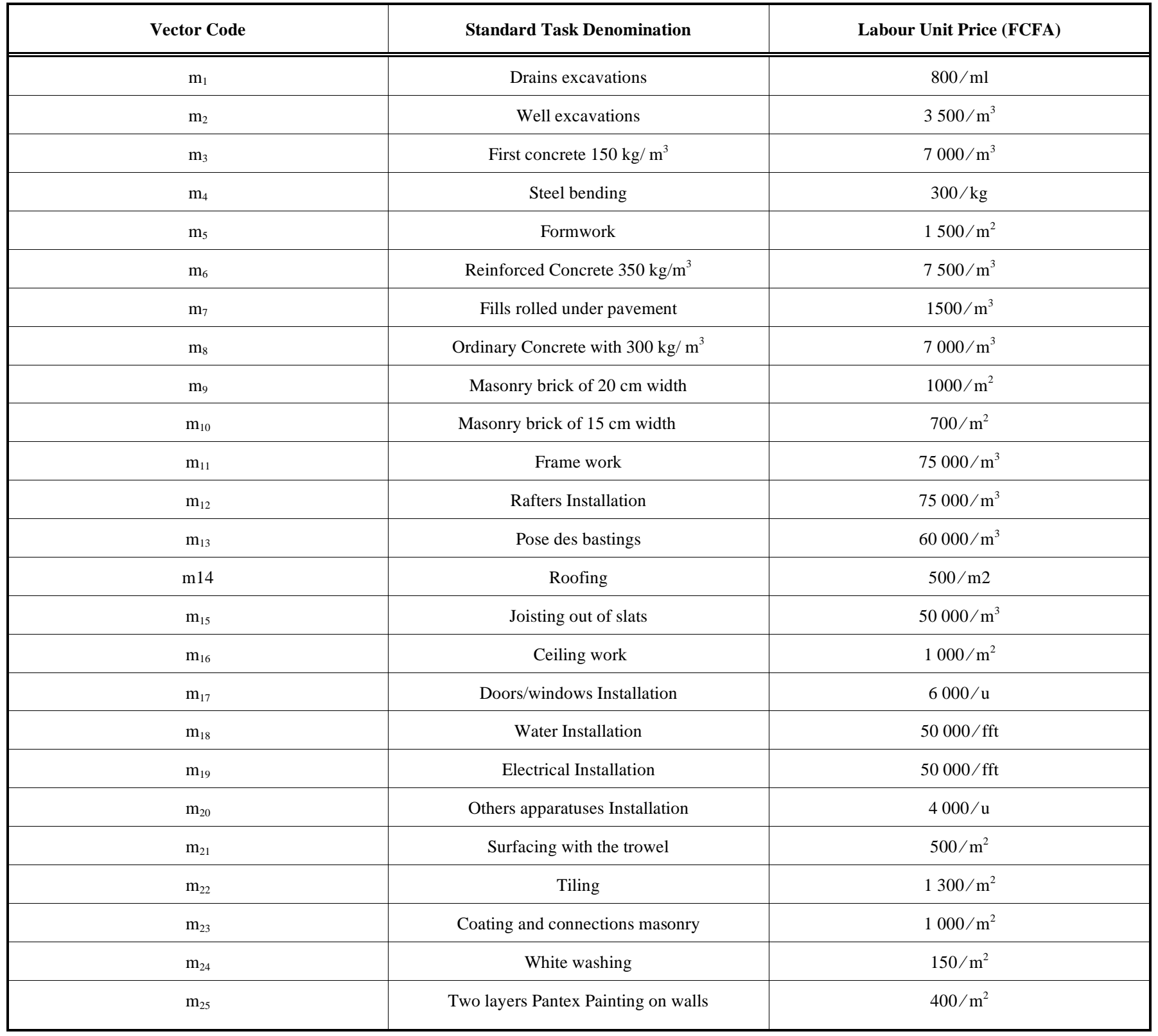

work quantity to be carried out and the unit prices respectively.

The work quantity matrix $\left[\mu_{s, t}\right]$ :

$\left[\mu_{s, t}\right]$ represents the volume of work to be carried out for each sub structure. The index $s$ indicates the total number of sub structures, and $t$ the total number of standards tasks constituting the construction project.

The unit cost matrix $\left[U_{3, t}\right]$

$\left[U_{3, t}\right]$ represents the unit price by task and into the three components as: Labour, Materials and management Means. According to the above definitions and the equation 10, then:

$$
\left\{\begin{array}{l}
{\left[\mu_{s, t}\right]=\left[\begin{array}{cccc}
\mu_{11} & \mu_{12} & \ldots & \mu_{1 t} \\
\mu_{21} & \mu_{22} & \ldots & \mu_{2 t} \\
\ldots & \ldots & \ldots & \ldots \\
\mu_{s 1} & \mu_{s 2} & \ldots & \mu_{s t}
\end{array}\right] ;} \\
\text { and }:\left[U_{3, t}\right]=\left[\begin{array}{llll}
u_{11} & u_{12} & \ldots & u_{1 t} \\
u_{21} & u_{22} & \ldots & u_{2 t} \\
u_{31} & u_{32} & \ldots & u_{3 t}
\end{array}\right] ;
\end{array}\right.
$$

$\forall 1 \leq i \leq s, \forall 1 \leq j \leq t ; \mu_{i j}$ indicates the quantity of work necessary for the realization of sub structure SOi and relative with the standard task $j$.

$\forall 1 \leq j \leq t:$ 
$u_{1 j}$ indicates the labour unit price in the execution of the standard task $\mathrm{j}$;

$u_{2 j}$ indicates the materials cost relate to standard task $\mathrm{j}$; and $u_{3 j}$ indicates the management cost relate to standard task $j$.

From the two matrices $\left[\mu_{s, t}\right]$ and $\left[U_{3, t}\right]$ in equation 11 , several other matrices are defined as follows:

The work quantity matrix per standard task $\left[\mu_{1, t}\right]$ :

$\left[\mu_{1, t}\right]$ is obtained from equation 11 by the following formula (equation 12):

$$
\left\{\begin{array}{c}
{\left[\mu_{1, t}\right]={ }^{T}\left[I_{s, 1}\right] \times\left[\mu_{s, t}\right]=\left[I_{1, s}\right] \times\left[\mu_{s, t}\right]} \\
=\left[\begin{array}{ccccc}
1 ; & 1 ; & \ldots ; & 1
\end{array}\right] \times\left[\begin{array}{cccc}
\mu_{11} & \mu_{12} & \ldots & \mu_{1 t} \\
\mu_{21} & \mu_{22} & \ldots & \mu_{2 t} \\
\ldots & \ldots & \ldots & \ldots \\
\mu_{s 1} & \mu_{s 2} & \ldots & \mu_{s t}
\end{array}\right]=\left(\mu_{j}\right) ;
\end{array}\right.
$$

with $: \mu_{j}=\sum_{i=1}^{s} \mu_{i j} ; \forall 1 \leq j \leq t$

The unit cost matrix by standard task $\left[U_{1, t}\right]$ : $\left[U_{1, t}\right]$ is a row vector obtained from equation 11 by:

$$
\left\{\begin{array}{l}
{\left[U_{1, t}\right]={ }^{T}\left[I_{3,1}\right] \times\left[U_{3, t}\right]=\left[I_{1,3}\right] \times\left[U_{3, t}\right]} \\
=\left[\begin{array}{lll}
1 ; & 1 ; & 1
\end{array}\right] \times\left[\begin{array}{llll}
u_{11} & u_{12} & \ldots & u_{1 t} \\
u_{21} & u_{22} & \ldots & u_{2 t} \\
u_{31} & u_{32} & \ldots & u_{3 t}
\end{array}\right]=\left(u_{j}\right) ; \\
u_{j}=\sum_{k=1}^{3} u_{k j} ; \forall 1 \leq j \leq t
\end{array}\right.
$$

\section{Cost Estimation by Matrix operations}

The following matrices are presented as the product of others matrices.

The cost by task matrix per sub structure $\left[C_{s, t}\right]$ :

This matrix $\left[C_{s, t}\right]$ is obtained as a product of matrices from equation 11 and equation 13, and it calculates the total cost of realization per task, for each sub structure:

If $\left[U_{t, t}^{\prime}\right]$ indicates the diagonal matrix resulting from $\left[U_{1, t}\right]$, then:

$$
\left\{\begin{array}{l}
{\left[C_{s, t}\right]=\left[\mu_{s, t}\right] \times\left[U_{t, t}^{\prime}\right]} \\
=\left[\begin{array}{cccc}
\mu_{11} & \mu_{12} & \ldots & \mu_{1 t} \\
\mu_{21} & \mu_{22} & \ldots & \mu_{2 t} \\
\ldots & \ldots & \ldots & \ldots \\
\mu_{s 1} & \mu_{s 2} & \ldots & \mu_{s t}
\end{array}\right] \times\left[\begin{array}{cccc}
u_{11}^{\prime} & 0 & \ldots & 0 \\
0 & u_{22}^{\prime} & \ldots & 0 \\
\ldots & \ldots & \ldots & \ldots \\
0 & 0 & \ldots & u_{t t}^{\prime}
\end{array}\right] \\
=\left(c_{i j}\right) ; \quad \ldots \\
c_{i j}=\mu_{i j} \times u_{j j}^{\prime}, u_{j j}^{\prime}=\sum_{k=1}^{3} u_{k j} ; \forall 1 \leq j \leq t
\end{array}\right.
$$

The index $k$ refers to each of the three components of construction cost:

$k=1$ indicates the labour cost;

$k=2$, materials cost;

$k=3$, the management cost. In the following section, the matrices resulting from the project data are used to determine the costs matrices as follows:

The matrix construction cost by sub structure $\left[C_{1, s}\right]$. $\left[C_{1, s}\right]$ is obtained from equation 14 as follows:

$$
\left\{\begin{array}{l}
{\left[C_{1, s}\right]=\left[I_{1, t}\right] \times{ }^{T}\left[C_{s, t}\right]} \\
=\left[\begin{array}{cccc}
1 ; & 1 ; & \ldots & 1
\end{array}\right] \times\left[\begin{array}{llll}
c_{11} & c_{21} & \ldots & c_{s 1} \\
c_{12} & c_{22} & \ldots & c_{s 2} \\
\ldots & \ldots & \ldots & \ldots \\
c_{1 t} & c_{2 t} & \ldots & c_{s t}
\end{array}\right] \\
=\left(c_{i}^{\prime}\right) ; c_{i}^{\prime}=\sum_{j=1}^{t} c_{i j} ; \forall 1 \leq i \leq s ; 1 \leq j \leq t
\end{array}\right.
$$

The matrix cost by component $\left[C_{3, t}\right]$ :

$\left[C_{3, t}\right]$ is obtained from equation 11 and equation 12 .

It gives the cost of construction in the three factors: Labour, Materials and management Means:

If $\left[\mu_{t, t}^{\prime}\right]$ indicates the diagonal matrix resulting from $\left[\mu_{t, t}\right]$, then:

$$
\left\{\begin{array}{l}
{\left[C_{3, t}\right]=\left[U_{3, t}\right] \times\left[\mu_{t, t}^{\prime}\right]} \\
=\left[\begin{array}{llll}
u_{11} & u_{12} & \ldots & u_{1 t} \\
u_{21} & u_{22} & \ldots & u_{2 t} \\
u_{31} & u_{32} & \ldots & u_{3 t}
\end{array}\right] \times\left[\begin{array}{cccc}
\mu_{11}^{\prime} & 0 & \ldots & 0 \\
0 & \mu_{22}^{\prime} & \ldots & 0 \\
\ldots & \ldots & \ldots & \ldots \\
0 & 0 & \ldots & \mu_{t t}^{\prime}
\end{array}\right] \\
=\left(\tilde{c}_{k j}\right) ; \tilde{c}_{k j}=u_{k j} \times \mu_{j j}^{\prime} ; \forall 1 \leq k \leq 3 ; 1 \leq j \leq t \\
\mu_{j j}^{\prime}=\sum_{i=1}^{s} \mu_{i j}, \forall 1 \leq j \leq t
\end{array}\right.
$$


The matrix construction cost by task $\left[C_{1, t}\right]$. $\left\{\begin{array}{l}{\left[C_{1, t}\right]=\left[I_{1,3}\right] \times\left[C_{3, t}\right]} \\ =\left[\begin{array}{lll}1 ; & 1 ; & 1\end{array}\right] \times\left[\begin{array}{llll}\tilde{c}_{11} & \tilde{c}_{12} & \ldots & \tilde{c}_{1 t} \\ \tilde{c}_{21} & \tilde{c}_{22} & \ldots & \tilde{c}_{2 t} \\ \tilde{c}_{31} & \tilde{c}_{32} & \ldots & \tilde{c}_{3 t}\end{array}\right]=\left(c_{j}{ }_{j}\right)\end{array}\right.$

The labour cost results then from the matrix $\left[C_{3, t}\right]$ in equation 16 by the following formula in equation 18 :

$C_{M O}=\sum_{j=1}^{t} c_{1 j}=\sum_{j=1}^{t} u_{1 j} \times \boldsymbol{\mu}_{j j}^{\prime}$

The total cost of construction can be obtained by carrying out the sum of the elements of the matrices

$\left[C_{1, t}\right],\left[C_{3, t}\right]$ and $\left[C_{1, s}\right]$, respectively given by equation 17 , equation 16 and equation 15 .

$C_{T}=\sum_{j=1}^{t} C_{j}^{\prime \prime}=\sum_{k=1}^{3} \sum_{j=1}^{t} \tilde{c}_{k j}=\sum_{i=1}^{s} c_{i}^{\prime}$

$\mathrm{i}$ indicates the sub structure Soi ; $\mathrm{j}$ indicates the elementary task; $\mathrm{k}$ indicates factors (labour, materials, management Means.

\section{RESULTS}

In this section we will apply the approach in cost and schedule determination for self constructors

\section{The Choice of an Urban Building Plan}

According to the results of the surveys carried out in 1993 in Yaounde urban council [16], 43\% of housing have their useful area ranging between 100 and $150 \mathrm{~m} 2$. In addition, a previous study revealed that the average size of a modest urban building, in Cameroon contains about six (06) people [17]. In accordance with the architectural standards on the minimal useful areas, this urban household structure leads us to a distribution plan being made up of seven parts: a sitting room, a kitchen, two washing rooms and four bedrooms, being able to extend on a useful surface area from $120 \mathrm{~m} 2$. An example of Standard plan of urban lodging of $120 \mathrm{~m}$ is shown in additional sheet (Appendix 1) with the following partial areas:Useful areas: parlour: 25,75 $\mathrm{m} 2$; Room n1: 15,40 m2; Room 2: 10,10 m2 ; Room 3: 11,15 m2 ; toilet 1: $3,70 \mathrm{~m} 2$; toilet $2: 3 \mathrm{~m} 2$; dinning room: $15 \mathrm{~m} 2$; kitchen: $9,90 \mathrm{~m} 2$; Corridor: $26 \mathrm{~m} 2$

\section{Case Study}

M Meka is a civil servant with additional income which can reach 250000 francs CFA per month. He decides on year 2005 to build his house whose plan is quite the same type as the one described before. He had bought a $350 \mathrm{~m}^{2}$ portion of ground two years before. Then, the self builder asks some advice from technicians in order to know how much this project will cost and after how many years this project will finish.
With MASTA approach, the self builder can get the following decomposition of the project into 25 elementary tasks.

The determination of the matrices in the above section will permit to self constructor realise the building progressively with respect to the funds he has. These following Tables $(\mathbf{2}, \mathbf{3}$, and $\mathbf{4})$ present partial costs and schedule.

From equation 9 we use the Standard tasks in Table 1, then:

$$
\begin{aligned}
& \vec{m}_{1}=(800,0,0, \ldots, 0,0) ; \vec{m}_{2}=(0,3500,0, \ldots, 0,0) ; \ldots ; \\
& \vec{m}_{j}=\left(0,0, \ldots, \delta_{j}, \ldots, 0,0\right) ; \ldots ; \vec{m}_{25}=(0,0, \ldots, 0,400)
\end{aligned}
$$

Using the substructures named in Table 2 we have from equation 11 the following matrices.

$\left\{\begin{array}{c}{\left[\mu_{11 ; 25}\right]=\left[\begin{array}{cccc}\mu_{11} & \mu_{12} & \ldots & \mu_{1 ; 25} \\ \mu_{21} & \mu_{22} & \ldots & \mu_{2 ; 25} \\ \ldots & \ldots & \ldots & \ldots \\ \mu_{11 ; 1} & \mu_{11 ; 2} & \ldots & \mu_{11 ; 25}\end{array}\right] ;} \\ \text { and }:\left[U_{3 ; 25}\right]=\left[\begin{array}{cccc}800 & 3500 & \ldots & 400 \\ u_{21} & u_{22} & \ldots & u_{2 ; 25} \\ u_{31} & u_{32} & \ldots & u_{3 ; 25}\end{array}\right]\end{array}\right.$

The application of matrix calculation with MATLAB 6 SOFWARE gives the following results.

The labour cost of the first task « diggings » with respect to the first sub structure S01 « Foundation + Pavement + first Chaining» is obtained by the first element $\mathrm{C}_{11}$ of the matrix $\left[C_{s, t}\right]$ (Appendix $\mathbf{2}$ and $\mathbf{3}$ )

Then, $\mathrm{C}_{11}=0.1243 \times 1000000=124300 \mathrm{FCFA}$

For the sub structure $\mathrm{SO}_{1}$ the application of the equation (8) gives the following vector:

$\left\{\begin{array}{l}\overrightarrow{M O}_{1}=\sum_{j=1}^{25} \mu_{i, j} \vec{m}_{j}=111 \vec{m}_{1}+7.36 \vec{m}_{2}+2.57 \vec{m}_{3} \\ +66.16 \vec{m}_{4}+242 \vec{m}_{5}+27.57 \vec{m}_{6}+6.05 \vec{m}_{7} \\ +9 \vec{m}_{8}+8.53 \vec{m}_{9}+0.5 \vec{m}_{18}\end{array}\right.$

Thus the labour cost of the sub structure $\mathrm{SO}_{1}$ is equal to:

$$
\left\{\begin{array}{l}
\mathbf{C}_{\text {MO1 }}=111 \times 800+7.36 \times 3500+2.57 \times 7000 \\
+66.16 \times 1000+242 \times 300+27.57 \times 1500 \\
+6.05 \times 7500+9 \times 7000+8.53 \times 700 \\
+0.5 \times \mathbf{5 0 0 0 0}=\mathbf{4 5 6} \mathbf{2 5 0} \text { FCFA }
\end{array}\right.
$$

From equation 18 , the total labour cost is written as follows: 
Table 2. Partial Labour Cost Per Substructure

\begin{tabular}{|c|c|c|}
\hline Sub Structure & Denomination & Labour Cost \\
\hline \hline $\mathrm{SO}_{1}$ & Foundation + Pavement \\
& + First Chaining & 220100 \\
\hline $\mathrm{SO}_{2}$ & Wall Elevation with Masonry Brick & 137985 \\
\hline $\mathrm{SO}_{3}$ & Columns+ Lintels & 371513 \\
\hline $\mathrm{SO}_{4}$ & Second Chaining & 121000 \\
\hline $\mathrm{SO}_{5}$ & Frame and Cover & 120000 \\
\hline $\mathrm{SO}_{6}$ & Ceiling & 45000 \\
\hline $\mathrm{SO}_{7}$ & Joinery & 17500 \\
\hline $\mathrm{SO}_{8}$ & Plumbing & 589800 \\
\hline $\mathrm{SO}_{9}$ & Electrical Installation & 39520 \\
\hline $\mathrm{SO}_{10}$ & Interior and Exterior Coatings & 546345 \\
\hline $\mathrm{SO}_{11}$ & Sealed Coatings & $\mathbf{2 6 6 5 0 1 3}$ \\
\hline & Internal and External Painting & Total \\
\hline
\end{tabular}

$C_{\overline{M O}}=\sum_{i=1}^{11} \overrightarrow{M O}_{i}=\sum_{i=1}^{11} \sum_{j=1}^{25} \mu_{i, j} \vec{m}_{j}=\sum_{j=1}^{25} \eta_{j} \vec{m}_{j} ;$

Then, $C_{M O}=\sum_{1}^{25} C_{1 j}=2665013$ CFA

From equation 19 , the total cost of construction for this example is equal to:

$$
\begin{aligned}
& C_{T}=\left|\left[C_{1, t}\right]\right|=\left|\left[C_{3, t}\right]\right|=\left|\left[C_{1, s}\right]\right|=10327094 \text { F CFA } \\
& C_{T}=\sum_{j=1}^{t} c_{j}^{\prime \prime}=\sum_{k=1}^{3} \sum_{j=1}^{25} \tilde{c}_{k j}=\sum_{i=1}^{11} c_{i}^{\prime}=10327094 \quad \text { FCFA }
\end{aligned}
$$

Then M Meka need about 10327094 F CFA for the project. M Meka is not able to have a credit because his salary is low. Then he can not have at the same time all the money that the project need. But he can make sacking in two different associations (family and colleges) in order to save 40000 FCFA and 50000 FCFA respectively. If each group contains at least 10 persons, we suppose that M Meka takes 500000 FCFA at the first month in the second group and saves; six months after he takes 400000 FCFA from the first sacking group. With 900000 FCFA, the project can begging by the first sub structure S01.

Then this project will be achieved after five years.

According to equation 7 , the application of an statistical model obtained from a few projects give the following results in Table 5 .

Table 3. Partial Cost Per Substructure

\begin{tabular}{|c|c|c|}
\hline Sub Structure & Denomination of the Sub Structure & 1492044 \\
\hline \hline $\mathrm{SO}_{1}$ & Foundation + Pavement + First Chaining & 880400 \\
\hline $\mathrm{SO}_{2}$ & Wall Elevation with Masonry Brick & 551940 \\
\hline $\mathrm{SO}_{3}$ & Columns+ Lintels + Second Chaining & 1486050 \\
\hline $\mathrm{SO}_{4}$ & Frame and Cover & 484000 \\
\hline $\mathrm{SO}_{5}$ & Ceiling & 480000 \\
\hline $\mathrm{SO}_{6}$ & Joinery & 180000 \\
\hline $\mathrm{SO}_{7}$ & Plumbing & 70000 \\
\hline $\mathrm{SO}_{8}$ & Electrical Installation & 2359200 \\
\hline $\mathrm{SO}_{9}$ & Interior and Exterior Coatings & 158080 \\
\hline $\mathrm{SO}_{10}$ & Sealed Coatings & 2185380 \\
\hline $\mathrm{SO}_{11}$ & Internal and External Painting & $\mathbf{1 0 3 2 7 0 9 4}$ \\
\hline
\end{tabular}


Table 4. Self Builder Schedule

\begin{tabular}{|c|c|c|}
\hline Sub Structure & Denomination & Schedule \\
\hline $\mathrm{SO}_{3}$ & Columns + Lintels + Second Chaining & \multirow[t]{2}{*}{ 2nd year } \\
\hline $\mathrm{SO}_{4}$ & Frame and Cover & \\
\hline $\mathrm{SO}_{7}$ & Plumbing & \multirow[t]{3}{*}{3 rd and 4 th year } \\
\hline $\mathrm{SO}_{8}$ & Electrical Installation & \\
\hline $\mathrm{SO}_{9}$ & Interior and Exterior Coatings & \\
\hline $\mathrm{SO}_{10}$ & Sealed Coatings & 5 th year \\
\hline
\end{tabular}

Table 5. Application of a Regression Model

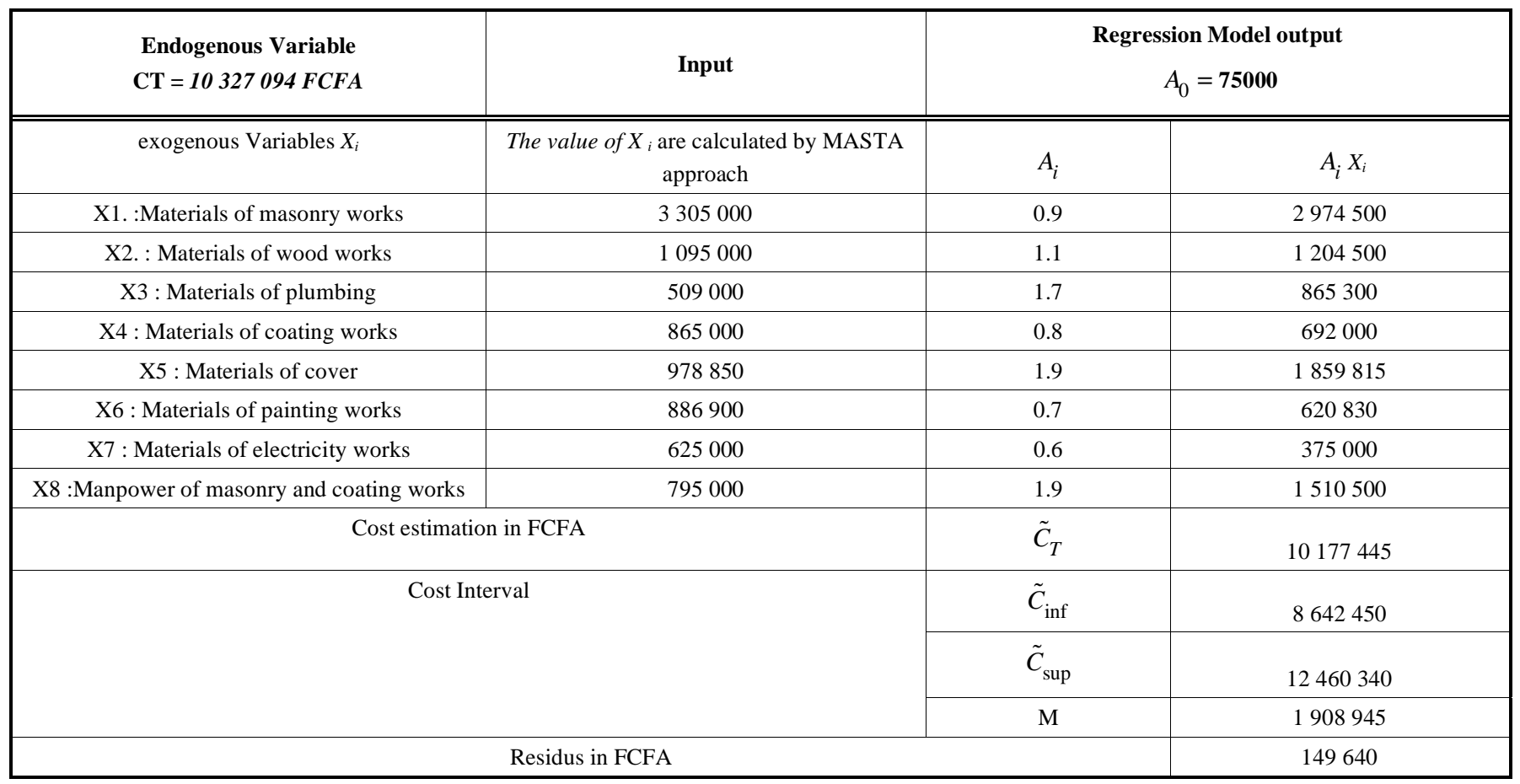

With the regression model RM the estimation of the total cost of this example of project is $K_{T}=10177445$ FCFA, with the cost interval as: $I_{f}=[\mathbf{8 6 4 2 4 5 0} F C F A ; 12460340 F C F A]$

The total cost calculated directly with the MASTA approach is CT = $10327094 \mathbf{F C F A}$ is inside the cost interval given by the statistical method.

\section{DISCUSSION}

The amount of the Labour cost represents $26 \%$ of the total construction cost; that is in conformity with the amount met in the specialized writings. For the studied case we high- lighted the impact of the labour cost in the self construction, by integrating that of materials and the management means already examined by other researchers. The decomposition of the total construction cost reveals the following proportions: $65 \%$ for materials; $25 \%$ for labour and $10 \%$ for management means [18, 19].

$$
\text { Thus } \mathrm{C}_{\mathrm{Mat}}=2,6 \times \mathrm{C}_{\mathrm{MO}} \text {; and } \mathrm{C}_{\mathrm{MO}}=2,5 \times C_{M G}
$$

In a preceding study [20], it was found that labour cost equals to 3.343.000 F CFA obtained for a building with the similar type $(110 \mathrm{~m} 2)$. By conveying the labour cost to the square meter unit, we obtain with our approach, for the studied case, a cost of $22.208 \mathrm{~F} \mathrm{CFA} / \mathrm{m} 2$, whereas in the above 
mentioned study they find $30.391 \mathrm{~F} \mathrm{CFA} / \mathrm{m} 2$. Thus, the approach based on tasks standards reveals a profit of $37 \%$ to weigh against the former simple matrix approach used by other researchers [20]. This disparity justifies the advantage of the new approach.

In this study, we insisted much more on the cost of labour factor of a construction project. However, for a total control of labour employed in self construction, we expect in the continuation of our study to integrate the times objective, in particular with an aim of optimizing the productivity of workers by task.

\section{CONCLUSION}

The model suggested has made it possible to establish a relationship between the labour cost and the quantity of work carried out with each stage of the construction project. Moreover, the relation highlighted between task and substructure would permit the self constructor to plan the expenditure according to the evolution of the project and the availability of its financial resources. Admittedly, the obser- vation of the datelines or schedule is one of the major objectives of any construction project, but in practice, this objective is not always an absolute priority for the self constructor, because the work evolution depends on the cash-flow. Although the time factor is not directly implied, this evaluation method of labour cost is likely to create for a workman a positive personal motivation approving the good observation of the schedule Indeed, in the informal sector where self construction dominates, the jobber manages actually his time according to his own interests. Thus, with the new approach by standards tasks, the overhead costs related to management, in particular in the choice of labour manpower are attenuated.

\section{ACKNOWLEDGEMENTS}

We want to sincerely thank Doctor G. E. KOUAMOU (National Advanced School of Engineering of the University of Yaounde I) for his advices about the MATLAB.6 software. Let us note at last that matrix algebra is also possible with the Excel software, but the computing time would be longer.

\section{APPENDIX 1}

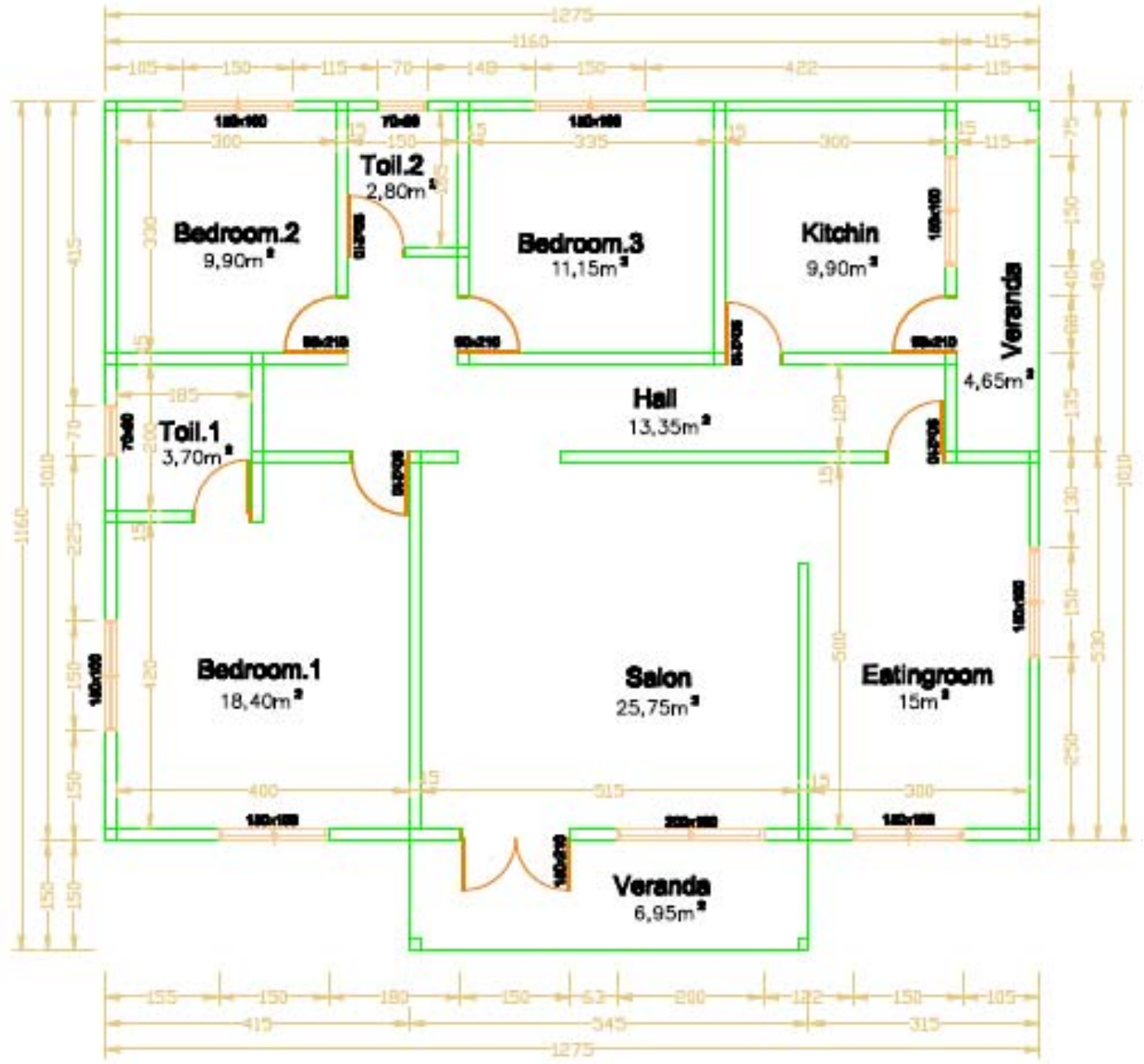

\section{Layout of urban housing Floor space : $120 \mathrm{~m}^{2}$}


APPENDIX 2: The matrix: $\left[C_{s, t}\right]=\left[\mu_{s, t}\right] \times\left[U_{t, t}^{\prime}\right]=\left(c_{i j}\right)$

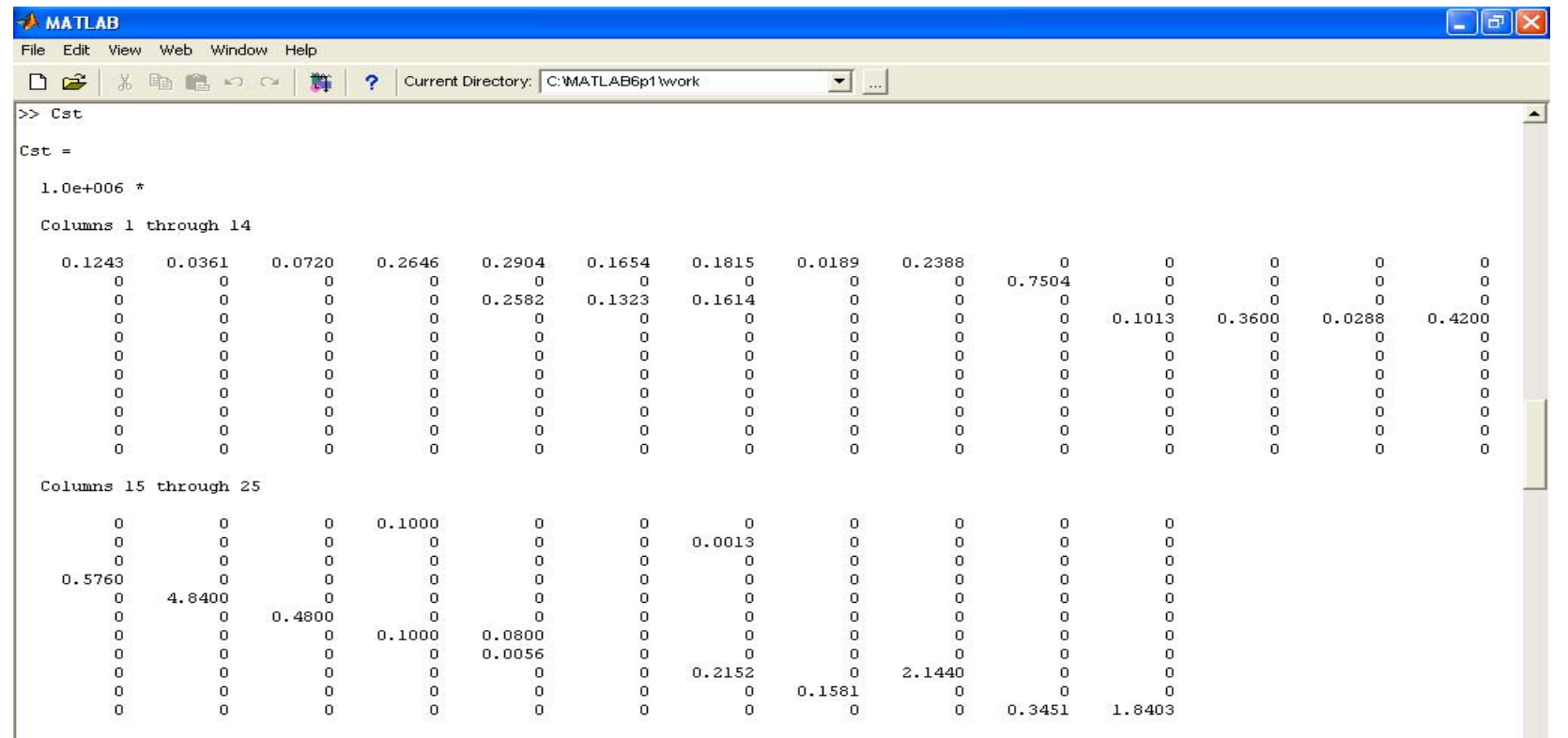

APPENDIX 3: $\left[C_{3, t}\right]=\left[U_{3, t}\right] \times\left[Q_{1, t}^{\prime}\right]=\left(C_{n m}\right)_{n=1,2,3 ; \quad m=1,2, \ldots, t}$

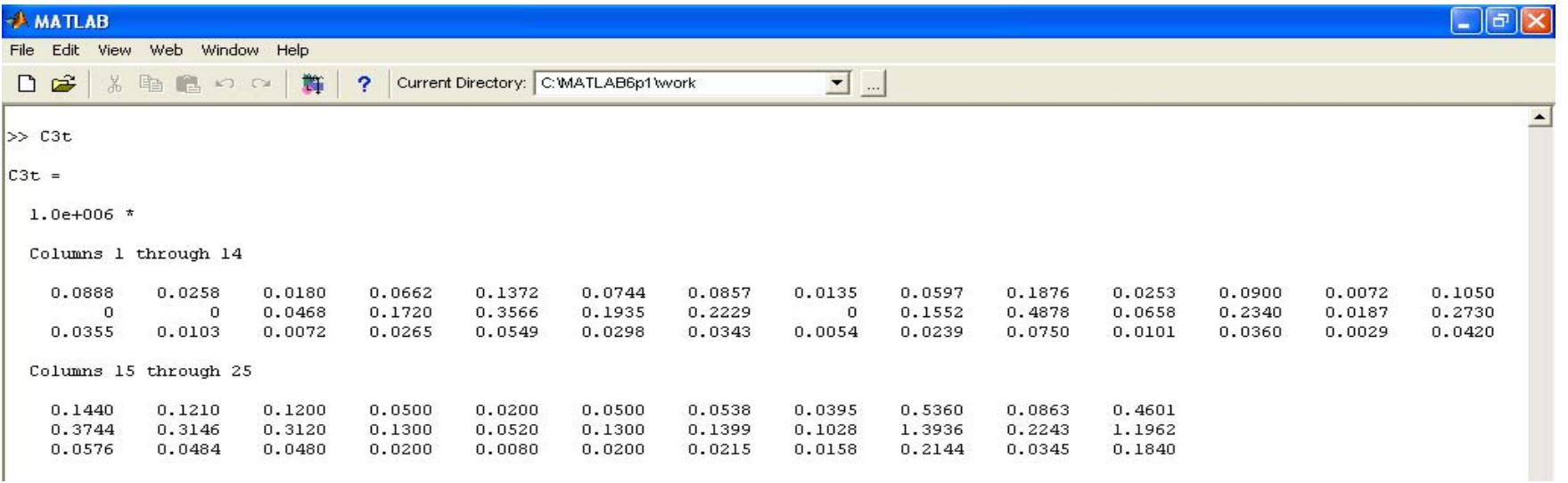

\section{REFERENCES}

[1] H. A. Odiyinka and A. Yusif, "The causes and effects of construction delays on completion cost of housing projects in Nigeria", Journal of Financial Management of Property and Construction, vol. 2, no. 3, pp. 31-44, 1997.

[2] O. P. Edem, O. P. A. Edem and O. Igwe, "Methodology for determining price variation in project execution", Journal of Construction Engineering and Management, vol. 127, no. 5, pp. 367-373, 2001.

[3] A. A. Aibinu and G. O. Jagboro, "The effects of construction delays on project delivery in Nigerian construction industry", International Journal of Project Management, vol. 20, no. 8, pp. 593-599, 2002.

[4] N. R. Mansfield, O. O. Ugwu and T. Doran, "Causes of delay and cost overruns in Nigerian construction project", International Journal of Project Management, vol. 12, no. 1, pp. 254-260, 1994.

[5] P. Louzolo-Kimbembe, "Contribution aux méthodes de maîtrise du coût de la construction dans les Pays en Développement: estimation du coût et optimisation dans un contexte hors délai", Thèse de $\mathrm{Ph}$. D, Ecole Nationale Supérieure Polytechnique de Yaoundé, Cameroon, p. 304, 2005.
[6] C. Pettang, P. Vermande and M. Zimmermann, "Secteur informel et production de l'habitat au Cameroun", Les Cahiers des Sciences Humaines, vol. 31, no. 34, 1995, pp. 883-903, [E-Book] Avalable: http://www.horizon.documentation.ird.fr/exl-doc/plein_textes: pleins_4/scl_hum/010004316.pdf [Date d'acquisition: 2007]

[7] R. Fokou, "Une nouvelle méthodologie de maîtrise des coûts de construction pour valoriser le secteur informel", Mémoire de fin d'études d'Ingénieur de conception en Génie Civil, Ecole Nationale Supérieure Polytechnique de Yaoundé, 2003.

[8] C. Pettang, G. E. Kouamou and P. Louzolo-Kimbembe, "Amélioration du processus de gestion du permis de construire dans les villes des Pays en Développement: cas de Yaoundé (Cameroun)", Journal of Decision Systems, Lavoisier, vol. 15, no. 1, pp. 83-95, 2006.

[9] C. Pettang, "Diagnostic de l'habitat urbain au Cameroun : l'urbanisme et habitat urbain", Presses Universitaires de Yaoundé, vol. 1, p. 176, 1998.

[10] P. Louzolo-Kimbembe and C. Pettang, "Contribution to the amelioration of the estimation method of construction cost's mastering in developing countries", International Journal on Architectural Sciences, vol. 7, no. 1, pp. 14-25, 2006.

[11] P. Rigo, "Evaluation analytique du coût de construction - optimisation des structures navales", (ANAST-ULG).PSI-28 Fév. 
2002. Available: www.anast.ulg.ac.be/Download.document.php, ID_ARTICLE=493 [Date d'acquisition: 2007].

[12] H. S. Lee and K. J. Yi, "Application of mathematical Matrix to integrate project schedule and cost", Journal of Construction Engineering and Management, vol. 125, no. 5, pp. 339-346, 1999.

[13] C. Pettang, L. Mbumbia and A. Foudjet, "Estimating building materials cost in urban housing construction projects, based on matrix calculation: the case of Cameroon", Construction and Building Materials, USA, Elsevier Science Ltd, vol. 11, no. 1, 1997 pp. 4755, pp. 47-55.

[14] R. P. Charrette and H. Marshall, UNIFORMAT II. "Elemental classification for building specifications, Cost estimating and Cost Analysis", NISTIR, vol. 6389, pp. 109, 1999.

[15] C. Pettang, "Habitat et stratégie de développement urbain au Cameroun: une approche de recherche-action basée sur l'élaboration d'outils d'aide à la décision", Mémoire d'Habilitation à Diriger les Recherches, Lyon, 2001.
[16] Mogue. "Coût de production et mode de production de l'habitat urbain: cas de Yaoundé," Mémoire de fin d'études d'Ingénieur de conception en Génie Civil, Ecole Nationale Supérieure Polytechnique de Yaoundé, 1993.

[17] J. E. Nguindjel, "Un modèle d'Aide et d'Appui á l'Auto construction urbaine au Cameroun", Mémoire de DEA en Science de l'Ingénieur, Ecole Nationale Supérieure Polytechnique de Yaoundé, 2000, p. 62.

[18] C. H. Kamgang and R. N. Bidime, "Etude comparative des coûts de construction en matériaux locaux et matériaux conventionnels", $A f$ rican Journal of Building Materials, vol. 1, No. 3, pp. 12 -24, 1999

[19] C. Pettang, T. T. Tamo and L. et Mbumbia, "Impact de la dévaluation sur l'habitat", Les Cahiers de l'Ocisca, vol. 9, no. 7, pp. 1-35, 1994.

[20] P. Louzolo-Kimbembe and C. Pettang, "A new approach for construction planning in developing countries: the substructure chaining diagram (SSCD)", Journal of Construction Research, vol. 7, no. 1-2, pp. 159-176, 2006.

Received: September 15, 2009

(c) Manjia et al.; Licensee Bentham Open .

This is an open access article licensed under the terms of the Creative Commons Attribution Non-Commercial License (http://creativecommons.org/licenses/by-nc/3.0/) which permits unrestricted, non-commercial use, distribution and reproduction in any medium, provided the work is properly cited. 